\title{
Direct interaction of ligand-receptor pairs specifying stomatal patterning
}

\author{
Jin Suk Lee, ${ }^{1}$ Takeshi Kuroha, ${ }^{1,5}$ Marketa Hnilova, ${ }^{2}$ Dmitriy Khatayevich, ${ }^{2}$ Masahiro M. Kanaoka, ${ }^{1,6}$ \\ Jessica M. McAbee, ${ }^{1}$ Mehmet Sarikaya, ${ }^{2}$ Candan Tamerler, ${ }^{2}$ and Keiko U. Torii ${ }^{1,3,4,7}$ \\ ${ }^{1}$ Department of Biology, ${ }^{2}$ Department of Materials Science and Engineering, Genetically Engineered Materials Science and \\ Engineering Center, ${ }^{3}$ Howard Hughes Medical Institute, University of Washington, Seattle, Washington 98195, USA; ${ }^{4}$ PRESTO, \\ Japan Science and Technology Agency, Tokyo 102-0075, Japan
}

\begin{abstract}
Valves on the plant epidermis called stomata develop according to positional cues, which likely involve putative ligands (EPIDERMAL PATTERNING FACTORS [EPFs]) and putative receptors (ERECTA family receptor kinases and TOO MANY MOUTHS [TMM]) in Arabidopsis. Here we report the direct, robust, and saturable binding of bioactive EPF peptides to the ERECTA family. In contrast, TMM exhibits negligible binding to EPF1 but binding to EPF2. The ERECTA family forms receptor homomers in vivo. On the other hand, TMM associates with the ERECTA family but not with itself. While ERECTA family receptor kinases exhibit complex redundancy, blocking ERECTA and ERECTA-LIKE1 (ERL1) signaling confers specific insensitivity to EPF2 and EPF1, respectively. Our results place the ERECTA family as the primary receptors for EPFs with TMM as a signal modulator and establish EPF2-ERECTA and EPF1-ERL1 as ligand-receptor pairs specifying two steps of stomatal development: initiation and spacing divisions.
\end{abstract}

[Keywords: biochemical interaction; cell type differentiation; peptide ligands; plant biology; receptor kinases; stomatal development; tissue patterning]

Supplemental material is available for this article.

Received September 26, 2011; revised version accepted November 29, 2011.

Functional tissue patterning in multicellular organisms relies on cell-cell interactions specifying cell fate. Proper stomatal patterning is critical for plant productivity and survival. Genetic studies in Arabidopsis have suggested that secreted peptides (EPIDERMAL PATTERNING FACTORS [EPFs]) are recognized by cell surface receptors with extracellular leucine-rich repeat (LRR) domains (ERECTA family LRR receptor kinases [LRR-RKs] and TOO MANY MOUTHS [TMM] LRR receptor-like protein [LRR-RLP]) to enforce stomatal patterning (Nadeau and Sack 2002; Shpak et al. 2005; Hara et al. 2007, 2009; Hunt and Gray 2009). Among EPF family genes, EPF1 and EPF2 are expressed in the late and early stages of stomatal precursors, respectively, and inhibit neighboring cells from adopting stomatal lineage fate (Hara et al. 2007, 2009; Hunt and Gray 2009). Their expression patterns, loss-of-function, and overexpression phenotypes place EPF1 and EPF2 as critical regulators of stomatal patterning. More recently,

Present addresses: ${ }^{5}$ Bioscience and Biotechnology Center, Nagoya University, Chikusa, Nagoya 464-8601, Japan; ${ }^{6}$ Graduate School of Science, Nagoya University, Chikusa, Nagoya 464-8601, Japan.

${ }^{7}$ Corresponding author.

E-mail ktorii@u.washington.edu.

Article published online ahead of print. Article and publication date are online at http://www.genesdev.org/cgi/doi/10.1101/gad.179895.111. Freely available online through the Genes \& Development Open Access option. two EPF-LIKE genes that are not expressed in the stomatal lineage, EPFL6/CHALLAH and EPFL9/STOMAGEN, were also found to influence stomatal development (Abrash and Bergmann 2010; Kondo et al. 2010; Sugano et al. 2010). However, these genes do not play a role in the inhibitory cell-cell communication between stomatal precursors and their neighbors within the developing epidermis. Three ERECTA family genes act synergistically to enforce stomatal patterning with $T M M$, which can positively or negatively regulate stomatal development depending on regionor genotype-specific context (Nadeau and Sack 2002; Shpak et al. 2005).

Although numerous models have been proposed explaining the actions of EPFs and ERECTA/TMM /Gray et al. 2008; De Smet et al. 2009; Rowe and Bergmann 2010; Rychel et al. 2010), their molecular interactions remain unclear. The system presents a particular challenge due to the complexity of receptor regulation and the structural properties of the ligands. The extracellular domain of ERECTA family RKs possesses 20 introns, many of which are required for proper expression and function (Karve et al. 2011). Thus, expressing ERECTA family RKs in nonplant, heterologous systems may not be informative. Furthermore, unlike many other ligands for LRRRKs (such as brassinosteroids or small peptides, including CLE peptides, phytosulfokine, and flg22) (Belkhadir and 
Chory 2006; Zipfel 2008; Matsubayashi 2010), EPFs belong to a family of secreted cysteine-rich peptides (CRPs) that are relatively large and require proper folding (tertiary structure) for their function (Higashiyama 2010). We therefore reasoned that in order to address the relevant biochemical interactions, one must use both functional receptors and bioactive peptides.

To understand how stomatal patterns are controlled by local cell-cell communication, it is imperative to establish the biochemical interactions of core ligands (EPF1 and EPF2) and receptors (ERECTA family RKs and TMM). Here we show direct evidence for the molecular associations of EPF peptides to ERECTA family RKs using coimmunoprecipitation (co-IP) assays and newly developed receptor biosensor chips. We further demonstrate the in vivo associations of these receptors. Our results indicate that the ERECTA family RKs are the primary receptors for EPFs, while TMM may function as a signal modulator. Finally, using bioactive EPF peptides that elicit unique developmental responses and blocking ERECTA family signaling in vivo, we delineated the in vivo specificity for two ligand-receptor pairs. EPF2-ERECTA and EPF1ERECTA-LIKE1 (ERL1) act during two critical steps of stomatal development: initiation of stomatal cell lineage and stomatal spacing, respectively. Our work reveals a new mode of action of RK signaling in plants and suggests a mechanism for how related yet unique signals are interpreted to trigger unique developmental responses in plants.

\section{Results}

EPF1 and EPF2 associate with ERECTA family in planta

We first tested whether EPF1 and EPF2 bind to TMM, ERECTA, and/or ERL1. ERL2 was not included in the analysis due to its minor role in stomatal patterning (Shpak et al. 2005). Induction of EPF1 or EPF2 in Arabidopsis inhibits stomatal differentiation, resulting in seedling lethality (Hara et al. 2007, 2009; Hunt and Gray 2009). This makes it difficult to obtain sufficient amounts of EPF peptides for biochemical analysis. We therefore used a Nicotiana benthamiana transient expression system (Voinnet et al. 2003) to combinatorially coexpress epitope-tagged ligand-receptor pairs and performed co-IP assays (Fig. 1; Supplemental Fig. 1). To ensure that proper ligand-receptor interactions would be reconstituted in $N$. benthamiana, we used ligand and receptor constructs that are functional when expressed in Arabidopsis (for functionality, see Figs. 2, 3).

EPF1 and EPF2 possess an $\mathrm{N}$-terminal signal peptide, a propeptide region with low sequence similarity, and a C-terminal predicted mature EPF peptide (MEPF) domain with eight conserved cysteines (Supplemental Fig. 1; Rychel et al. 2010; Shimada et al. 2011). Expression of EPF1-Flag and EPF2-Flag in $N$. benthamiana resulted in major products corresponding to epitope-tagged MEPF1 and MEPF2 as well as faint signals of higher molecular mass, which are likely partially processed propeptide (Fig. 1). Immunopurified EPF1Flag and EPF2-Flag conferred severe reductions in stomatal differentiation similar to EPF1 and EPF2 overexpression, respectively (Supplemental Fig. 2), indicating that tobaccoexpressed peptides are functional and bioactive.

The epitope-tagged full-length ERECTA and ERL1 were expressed under the control of their respective native promoters. To increase yield, we also expressed their kinasedeleted versions $(\Delta \mathrm{K})$ under the control of a strong CaMV35S promoter, since removal of the kinase domain of ERECTA increases protein stability (Shpak et al. 2003). Biochemical fractionation experiments show that ERECTA $\Delta \mathrm{K}$, ERL1 $\triangle \mathrm{K}$, and TMM expressed by $35 \mathrm{~S}$ promoters were predominantly localized in the membrane (microsomal) fraction (Supplemental Fig. 3), confirming that these fusion proteins are localized properly.

Both full-length ERECTA-YFP and ERL1-YFP as well as their kinase-deleted versions (ERECTA $\triangle \mathrm{K}$-GFP and ERL1 $\Delta \mathrm{K}-\mathrm{GFP}$ ) were able to coimmunoprecipitate EPF1Flag and EPF2-Flag (Fig. 1A-D). Thus, as with other LRRRKs, such as CLAVATA1 (CLV1) and PSKR (Shinohara et al. 2007; Ogawa et al. 2008), the kinase domain of ERECTA family proteins is not required for ligand binding. In contrast, TMM-GFP failed to coimmunoprecipitate EPF1-Flag (Fig. 1E), although EPF2-Flag signal was obtained by TMM-GFP co-IP (Fig. 1E). To examine the specificity of interactions, we performed co-IP assays using epitope-tagged LURE2, an unrelated CRP controlling pollen tube guidance in Torenia (Okuda et al. 2009). LURE2Flag did not coimmunoprecipitate with ERECTA $\Delta$ K-GFP, ERL1 $\Delta K-G F P$, or TMM-GFP (Supplemental Fig. 4). Likewise, no co-IP signals were detected when GFP was coexpressed with EPF1-Flag and EPF2-Flag (Fig. 1F). The results indicate that EPF1 and EPF2 associate with the ERECTA family in planta, while TMM may show differential binding to each EPF.

\section{Bioactive, recombinant MEPF1 and MEPF2 trigger unique responses in stomatal development}

To detect direct ligand-receptor binding, we moved into a synthetic system using receptor biosensor chips. For this purpose, we first produced bioactive, predicted mature epitope-tagged EPF1 and EPF2 peptides (MEPF1-His and MEPF2-His) from Escherichia coli (Materials and Methods; Fig. 2; Supplemental Figs. 1, 5). The C-terminal MEPF domain of EPF1/2 possesses eight cysteines that are predicted to form intramolecular disulfide bonds (Supplemental Fig. 1; Higashiyama 2010; Kondo et al. 2010; Matsubayashi 2010; Sugano et al. 2010). Hence, unlike small post-translationally modified peptides such as MCLV3 and phytosulfokine, proper refolding is critical for the biological activities of CRPs (Higashiyama 2010). We developed protocols for refolding both MEPF1 and MEPF2 expressed and purified from E. coli (see the Materials and Methods).

Application of refolded MEPF1-His $(2.5 \mu \mathrm{M})$ to Arabidopsis wild-type seedlings conferred an epidermis devoid of stomata with arrested stomatal precursors called meristemoids (Fig. 2A,B), a phenotype identical to induced EPF1 overexpression (Fig. 2C,D). Likewise, application of MEPF2-His $(2.5 \mu \mathrm{M})$ peptide solutions led to severe inhibition of asymmetric divisions initiating stomatal lineages 
Lee et al.

A

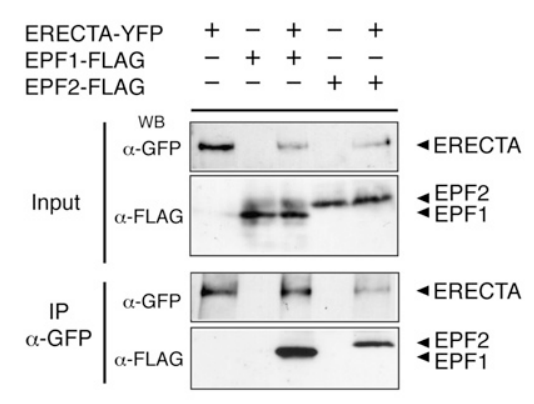

C

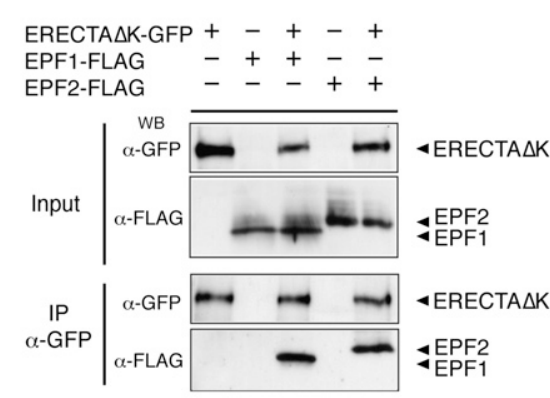

E

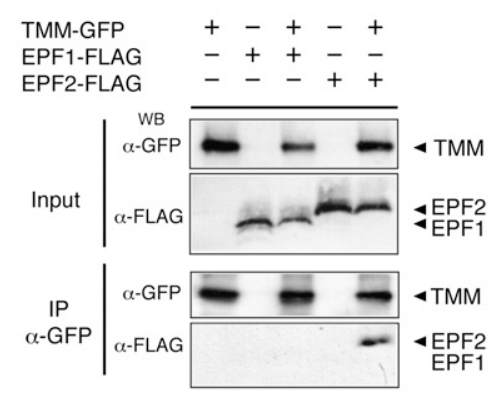

B

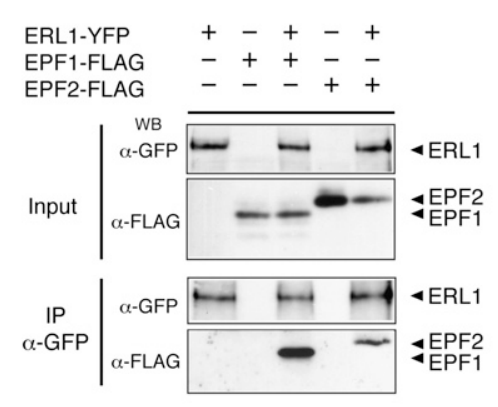

D

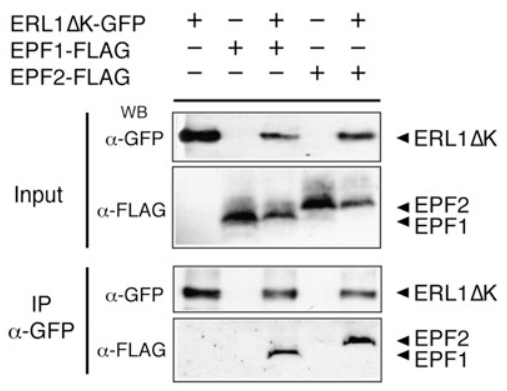

$\mathbf{F}$

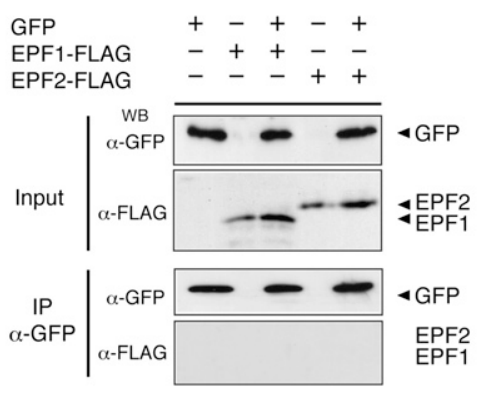

Figure 1. EPF1 and EPF2 associate with ERECTA and ERL1 but exhibit differential association with TMM in planta. Co-IP assays of epitope-tagged ligand-receptor pairs expressed in $N$. benthamiana leaves. (A) ERECTA (ERECTA-YFP) associates with EPF1 and EPF2. We observed that coexpression with EPFs results in reduced ERECTA-YFP signals, consistent with the previous report that full-length ERECTA protein is unstable (Shpak et al. 2005). (B) ERL1 (ERL1-YFP) associates with EPF1 and EPF2. $(C)$ Kinase-deleted ERECTA (ERECTA $\triangle \mathrm{K}-\mathrm{GFP}$ ) associates with EPF1 and EPF2. $(D)$ Kinase-deleted ERL1 (ERL1 $\triangle \mathrm{K}-\mathrm{GFP})$ associates with EPF1 and EPF2. (E) TMM does not associate with EPF1 but shows association with EPF2. $(F)$ Control GFP does not associate with EPF1 or EPF2. The faint, higher molecular bands in the input blots of EPF1-Flag and EPF2Flag likely represent variable unprocessed/ intermediate precursor peptides. All experiments were repeated at least four times.
(Fig. 2E,F), a phenotype identical to induced EPF2 overexpression (Fig. 2G,H). These observations demonstrate the unique biological activities of MEPF1 and MEPF2 in different steps of stomatal development, restricting initial asymmetric division and enforcing proper spacing. Furthermore, the results support the notion that, like EPFL9/Stomagen (Kondo et al. 2010; Sugano et al. 2010), MEPF1 and MEPF2 are mobile signals controlling stomatal development in a non-cell-autonomous manner.

\section{Direct binding of bioactive MEPF1 and MEPF2 \\ to plant-produced receptors on synthetic biosensor platform}

Purified, bioactive MEPF1 and MEPF2 peptides were used to perform ligand-receptor-binding assays using biosensor platforms of QCM (quartz crystal microbalance) and SPR (surface plasmon resonance) (Tamerler et al. 2006; Baltus et al. 2007). For both techniques, we first immobilized purified ERECTA $\triangle \mathrm{K}$-GFP, ERL1 $\triangle \mathrm{K}$-GFP TMM-GFP, or control GFP from $N$. benthamiana on gold surfaces via anti-GFP antibody linkages and then introduced the purified MEPF-His peptide solutions (Materials and Methods).

To accurately measure the amounts of bioactive peptide, we performed reverse-phase high-pressure liquid chromatography (HPLC) followed by mass spectrometry and bioassays. Properly folded (and bioactive) peptides were separated from misfolded (and inactive) forms, and their amounts were determined (Supplemental Figs. 6, 7).

Robust binding of MEPF1 and MEPF2 to the ectodomain of ERECTA and ERL1 was detected as a function of frequency change (for QCM) or the shift in SPR wavelength (for SPR) (Fig. 2I-N; Supplemental Fig. 8). Based on the SPR sensorgrams, the binding of MEPF1 to both ERECTA and ERL1 was rapid, saturable, and in similar kinetics (Fig. 2M). The QCM data support this observation (Fig. 2I). In contrast, no obvious binding of MEPF1 to TMM-GFP or control GFP was detected by either SPR or QCM (Fig. 2I,J,M). MEPF2, unlike MEPF1, exhibited binding to TMM in addition to ERECTA and ERL1 (Fig. 2K,L,N). The apparent affinity 

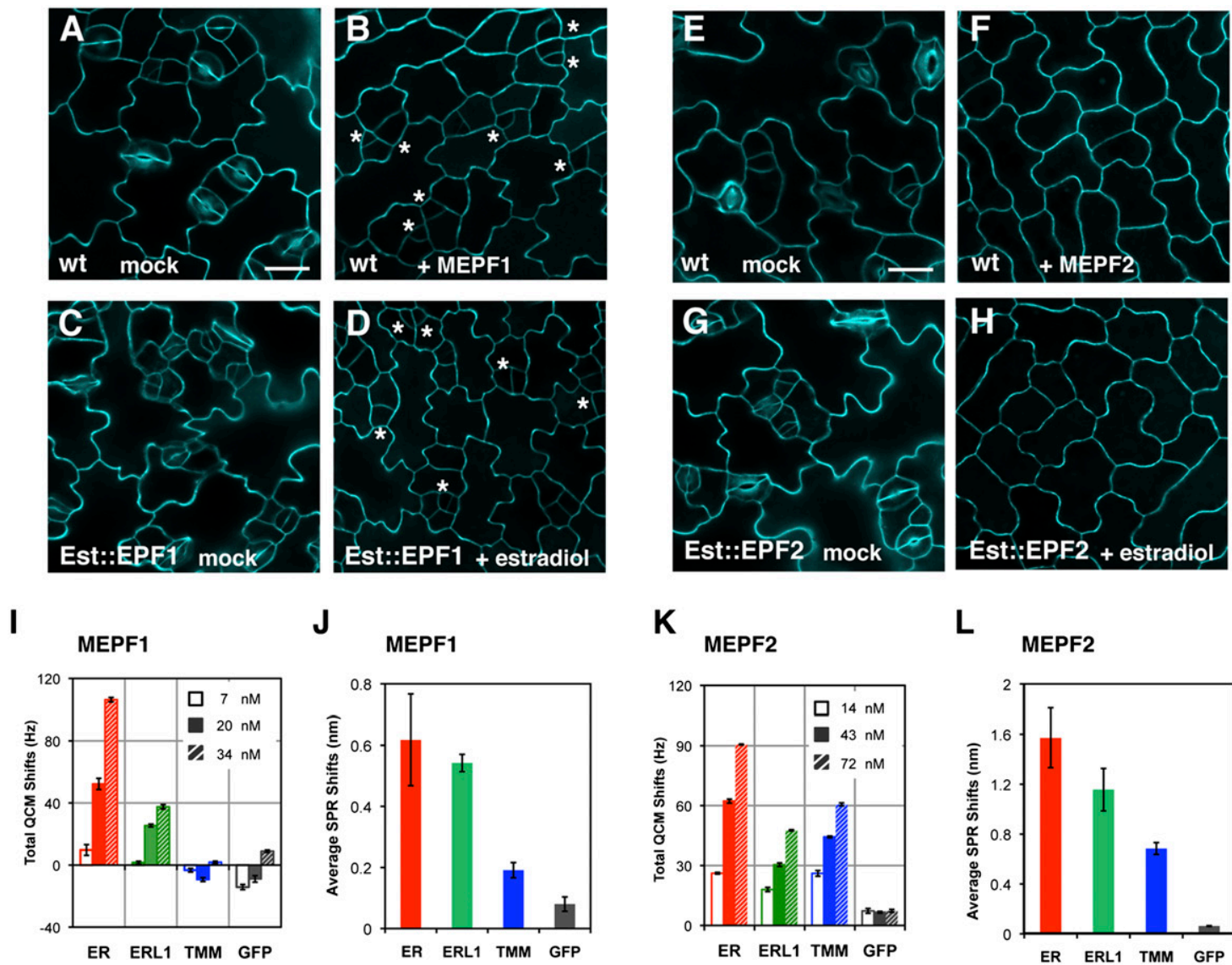

J

$\mathbf{K}$
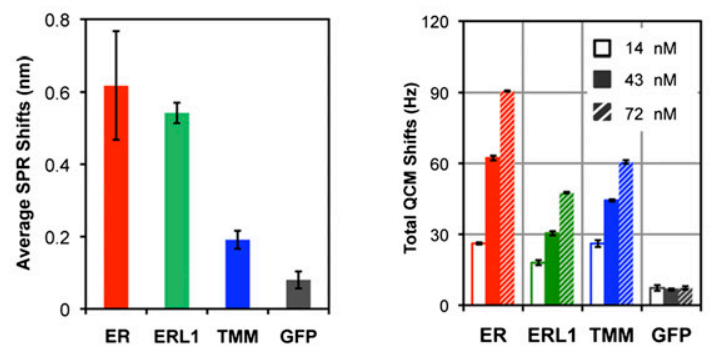

$\mathbf{L}$

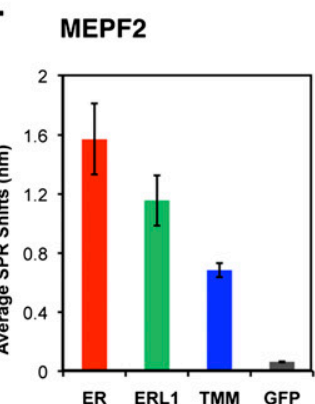

M

$\mathbf{N}$

MEPF1

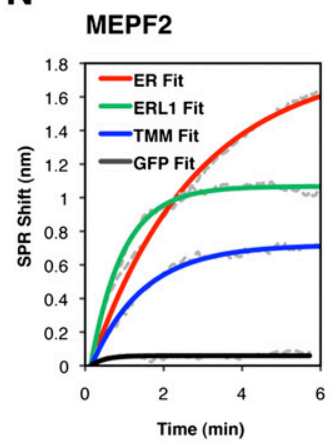

0
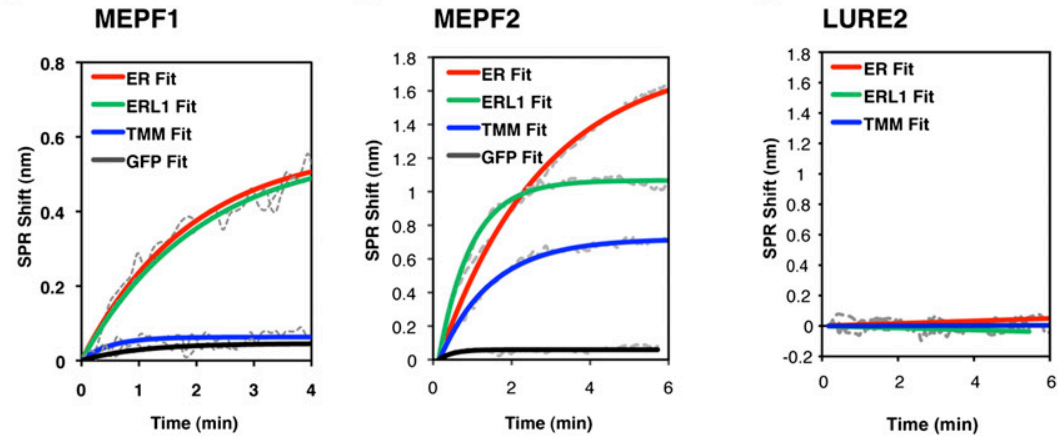

P

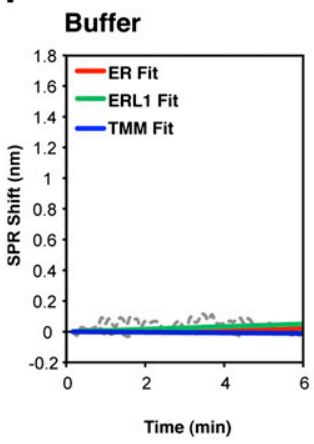

Figure 2. Production of bioactive, recombinant MEPF1 and MEPF2 peptides and detection of direct ligand-receptor binding. $(A-H)$ Confocal images of wild-type cotyledon epidermis grown $5 \mathrm{~d}$ in a buffer solution $(A, E$; mock), $2.5 \mu M$ MEPF1 $(B)$, or $2.5 \mu M$ MEPF2 $(F)$, and transgenic seedlings expressing estrogen-inducible EPF1 (Est::EPF1) $(C, D)$ or EPF2 (Est::EPF2) $(G, H)$ grown in the absence $(C, G$; mock) or presence $(D, H)$ of $5 \mu \mathrm{M}$ estradiol. (Asterisks) Arrested stomatal precursors. Images were taken under the same magnification. Bar, $20 \mu \mathrm{m}$. $(I-P)$ QCM and SPR analysis. $(I, K)$ Average frequency shifts for representative QCM analysis using biosensor chips immobilized with ERECTA $\Delta$ K-GFP (red), ERL1 $\Delta$ K-GFP (green), TMM-GFP (blue), and GFP alone (gray) recorded sequentially after injection of MEPF1 $(I)$ or MEPF2 $(K)$ at serial dilution concentrations of active peptides. Error bars, SD. $(J, L)$ Average SPR shifts with error bars (SEM). (M-P) Observed SPR kinetic sensograms fitted by least-square regression with a Langmuir adsorption model from representative SPR-binding assay upon injection $(t=0)$ of $300 \mathrm{nM}$ refolded peptide solution of MEPF1 $(M)$, MEPF2 (N), LURE2 $(O)$, or buffer only $(P)$ into biosensor chips immobilized with receptors as described above. SPR and QCM experiments were performed at least three times for each receptor using independent biosensor chips prepared for each method.

difference for TMM between MEPF1 and MEPF2 was consistently detected in three different methods (Figs. 1, 2; Supplemental Fig. 8). Additionally, we detected a difference in the binding kinetics of MEPF2 to ERECTA and ERL1, with ERECTA having higher saturation (Fig. 2N).
To address the specificity of ligand binding, we further performed SPR analysis using LURE2 (Okuda et al. 2009). LURE2 showed no binding to ERECTA, ERL1, or TMM under the same conditions (300 nM total refolded peptide solution) (Fig. 2O), and its sensorgram was identical to the 
Lee et al.
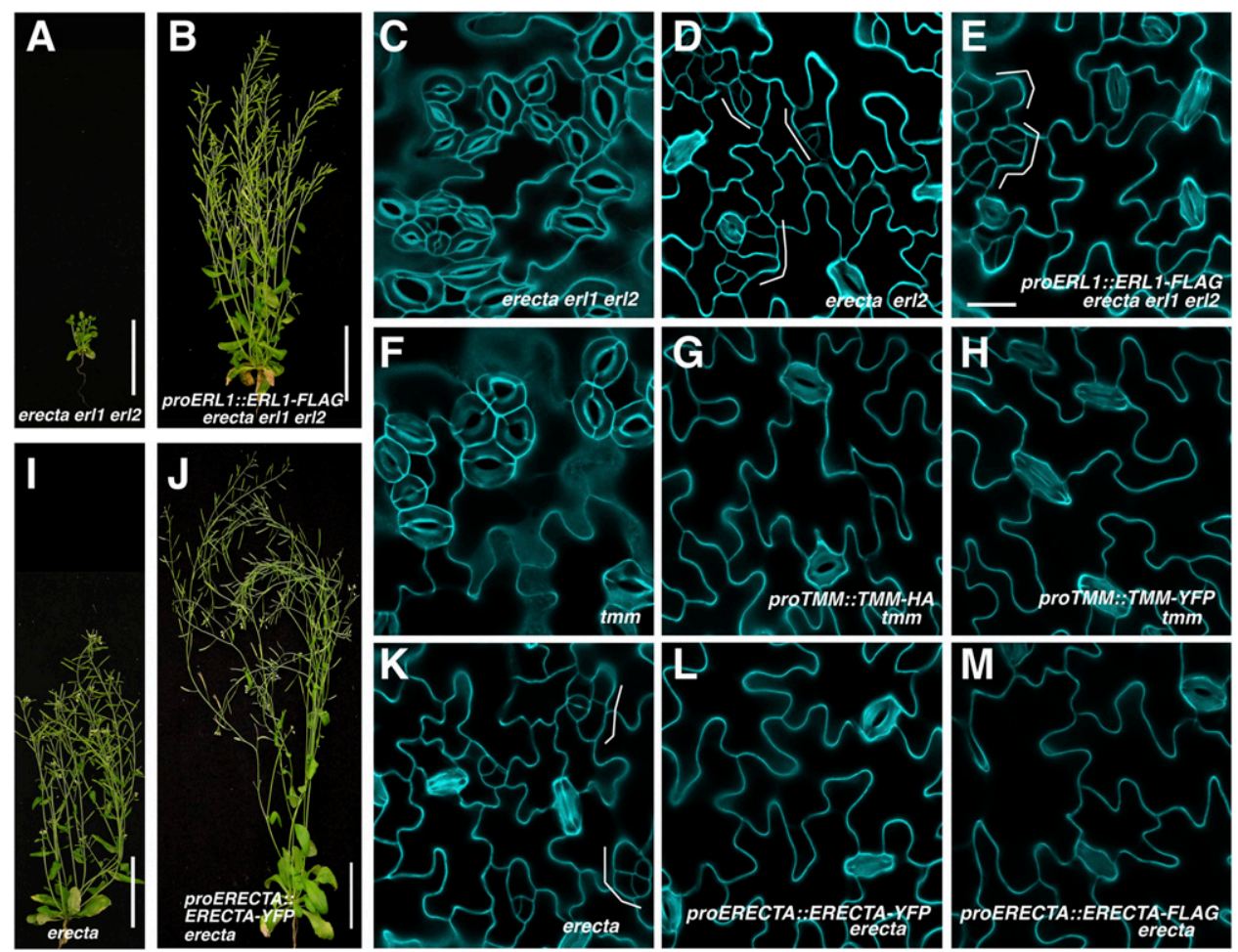

Figure 3. Epitope-tagged receptors are functional. Complementation of respective Arabidopsis mutant phenotypes by a series of epitope-tagged putative receptors. $(A, B)$ Six-week-old plants of erecta erl1 erl2 triple loss-of-function mutant $(A)$ and erecta erl1 erl2 expressing proERL1::ERL1-Flag $(B)$. $(C-E)$ Confocal microscopy of 12-d-old abaxial cotyledon epidermis of erecta erl1 erl2 (C), erecta er12 $(D)$, and erecta er11 erl2 expressing proERL1 ::ERL1-Flag $(E)$. The ERL1-Flag construct fully rescues both the growth defects $(A, B)$ as well as the stomatal clustering $(C, E)$ of erecta erl1 erl2, conferring an epidermal phenotype highly resembling that of erecta erl2. Note that the erl1 single mutant does not confer dwarfism or stomatal clustering. Brackets in $D$ and $E$ indicate arrested stomatal precursors typical of the erecta mutant background with functional ERL1 or ERL2. $(F-H)$ Twelve-day-old abaxial cotyledon epidermis of tmm $(F)$, proTMM::TMM-HA in tmm $(G)$, and proTMM::TMM-YFP in tmm $(H)$. Both proTMM::TMM-HA (G) and proTMM::TMM-YFP (H) rescue stomatal patterning defects seen in $t m m(F)$. (I-M) Six-week-old plants of erecta $(I)$ and erecta expressing proERECTA::ERECTAYFP $(J) .(K-M)$ Twelve-day-old abaxial cotyledon epidermis of erecta $(K)$ proERECTA::ERECTA-YFP in erecta $(L)$, and proERECTA:: ERECTA-Flag in erecta $(M)$. The epitope-tagged receptors fully rescue the growth defects $(I, I)$ and extra asymmetric division phenotype seen in erecta $(K$; brackets). Confirmed null (T-DNA knockout) alleles that do not accumulate any transcripts of respective receptor genes were used for all experiments. Full rescue of the erecta growth phenotype by proERECTA::ERECTA-Flag was described previously (Uchida et al. 2011). All confocal microscopy images were taken under the same magnification. Bars: whole-plant images, 5 $\mathrm{cm}$; confocal microscopy, $20 \mu \mathrm{m}$.

buffer-only control (Fig. 2P). Furthermore, heat denaturation of MEPF1 and MEPF2 severely compromised their binding to receptors (Supplemental Fig. 9). Together, the results demonstrate specific, direct binding of bioactive MEPF peptides to the ERECTA family RKs as well as their differential binding to TMM.

\section{In vivo association of ERECTA family RKs and TMM}

Unlike ERECTA family RKs, TMM lacks a cytoplasmic effector domain (Nadeau and Sack 2002). To clarify the role of TMM in ERECTA family-mediated signaling, we next investigated the physical associations of these receptors in vivo. For this purpose, we generated transgenic Arabidopsis plants expressing a series of epitope-tagged TMM, ERECTA, and ERL1 driven by their own native promoters. Because ERECTA requires introns for functionality (Karve et al. 2011), genomic DNA was used for the constructs. Epitope-tagged ERECTA, ERL1, and TMM res- cued their respective mutant phenotypes, indicating that they are functional (Fig. 3). Since ERL1 is functionally redundant, we introduced the epitope-tagged ERL1 into the erecta erl1 erl2 triple mutant to confirm its functionality (Fig. 3A-E). The epitope-tagged TMM, ERECTA, and ERL1 were detected in membrane (microsomal) fractions, consistent with their predicted subcellular localizations (Supplemental Fig. 10; Nadeau and Sack 2002; Shpak et al. 2004).

We subsequently generated double-transgenic Arabidopsis plants expressing pairwise combinations of functional epitope-tagged receptors and performed co-IP assays (Fig. 4). ERECTA-Flag protein was coimmunoprecipitated with ERECTA-YFP using anti-GFP antibody, indicating that ERECTA associates with itself in vivo (Fig. 4A). Likewise, co-IP experiments demonstrated in vivo association of ERL1 with itself (Fig. 4B). Thus, ERECTA family RKs form receptor homomers in vivo. In contrast, reciprocal co-IP assays using double-transgenic tmm seedlings 
A

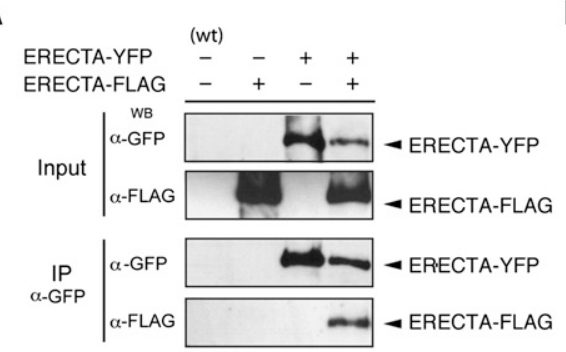

D

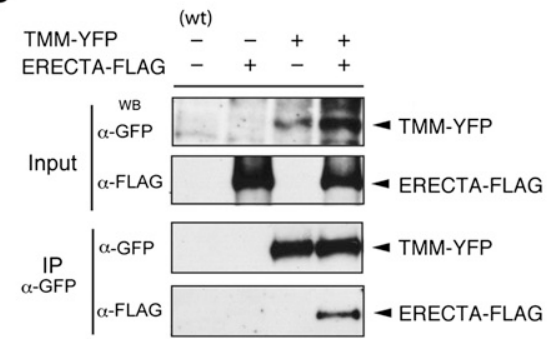

B

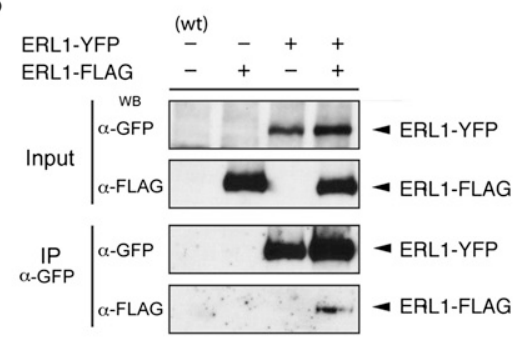

E

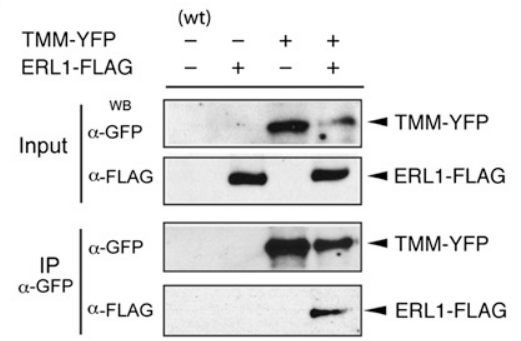

C

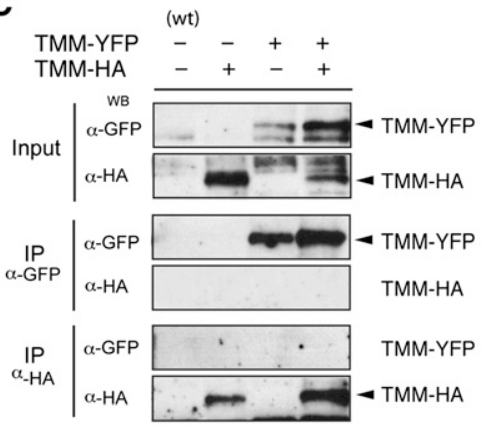

$\mathbf{F}$

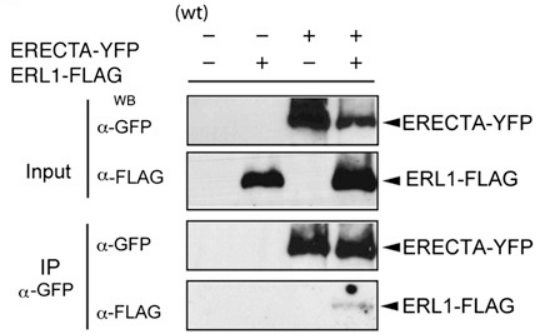

Figure 4. Molecular interactions of ERECTA family RKs and TMM in vivo. Arabidopsis wild-type (wt) or null mutant seedlings expressing epitope-tagged receptors are indicated in each panel. In each panel, both inputs and co-IP fractions (IP $\alpha$-GFP) were subjected to Western blot (WB) with anti-GFP $(\alpha$-GFP) or anti-Flag ( $\alpha$-Flag) antibodies. $(A)$ ERECTA associates with itself. $(B)$ ERL1 associates with itself. $(C)$ TMM does not associate with itself in vivo. Reciprocal co-IP assays resulted in no TMM bands in the co-IP fractions. (D) ERECTA associates with TMM. $(E)$ ERL1 also associates with TMM. $(F)$ ERECTA associates with ERL1, suggesting heteromerization among ERECTA family RKs. Immunoblots of inputs of TMM-HA and TMM-YFP yielded nonspecific bands. Co-IP experiments were performed at least three times.

expressing both proTMM::TMM-YFP and proTMM::TMMHA failed to precipitate TMM-HA or TMM-YFP by antiGFP or anti-HA antibody, respectively (Fig. 4C). This indicates that TMM does not form homomers in vivo. However, TMM-YFP and ERECTA-Flag as well as TMMYFP and ERL1-Flag associate with each other in vivo (Fig. 4D,E).

ERECTA and ERL1 exhibit unique yet overlapping expression patterns in developing epidermis, with ERECTA predominantly in the protoderm and ERL1 in meristemoids and SLGCs (Shpak et al. 2005). We thus tested whether they could form heterodimers in vivo. Indeed, co-IP experiments show that ERECTA-YFP associates with ERL1Flag (Fig. 4F). Taken together, the results suggest that the ERECTA family function as receptor homodimers as well as heteromers among them, while TMM modulates the signal transduction via association with the ERECTA family.

\section{In vivo specificity of ligand-receptor pairs controlling} two critical steps of stomatal development

Genetic studies have shown that EPF1 and EPF2 possess unique functions: EPF1 orients asymmetric spacing divisions to prevent stomatal pairing, while EPF2 inhibits asymmetric entry divisions initiating stomatal cell lineages (Hara et al. 2007, 2009; Hunt and Gray 2009). Consistently, the phenotypes of EPF1 and EPF2 overexpression (or MEPF1 and MEPF2 application) are different (Fig. 2; Hara et al. 2007, 2009). Genetically, however, both EPF1 and EPF2 require TMM and ERECTA family genes to function (Hara et al. 2007, 2009). How can different EPFs elicit distinct responses during stomatal development? The difference in binding affinities of receptors to each MEPF peptide, as seen for TMM (Figs. 1, 2), may determine specificity. In the case of ERECTA and ERL1, however, both receptors show robust ligand binding.

To dissect the in vivo developmental specificities between EPFs and the ERECTA family, we examined the phenotypic consequences of blocking specific ERECTA family signaling (Fig. 5; Supplemental Fig. 11). Simple lossof-function experiments do not suffice due to partial genetic redundancy, and severe stomatal clustering results only when the entire ERECTA family of genes is missing (Supplemental Fig. 11; Shpak et al. 2004, 2005). We introduced kinase-deleted versions of ERECTA and ERL1 driven by their native promoters into their respective knockout backgrounds. A removal of the ERECTA kinase domain confers severe dominant-negative effects (Shpak et al. 2003). Thus, replacing ERECTA and ERL1 with their respective dominant-negative versions will likely block all EPF signals normally perceived by ERECTA or ERL1 from further signal transduction.

Replacement of the endogenous ERECTA by its dominant-negative version (proERECTA ::ERECTA $\triangle K$-YFP in erecta) conferred a phenotype nearly identical to that of epf2: a vast increase in asymmetric entry divisions resulting in increased nonstomatal cell density (Fig. 5B,C; Supplemental Fig. $11 \mathrm{C}, \mathrm{D}, \mathrm{K})$. In contrast, proERL1 $\because: E R L 1 \Delta K$ CFP in erl1 led to modest stomatal pairing, a phenotype highly resembling that of epf1 (Fig. 5D,E; Supplemental 
Lee et al.

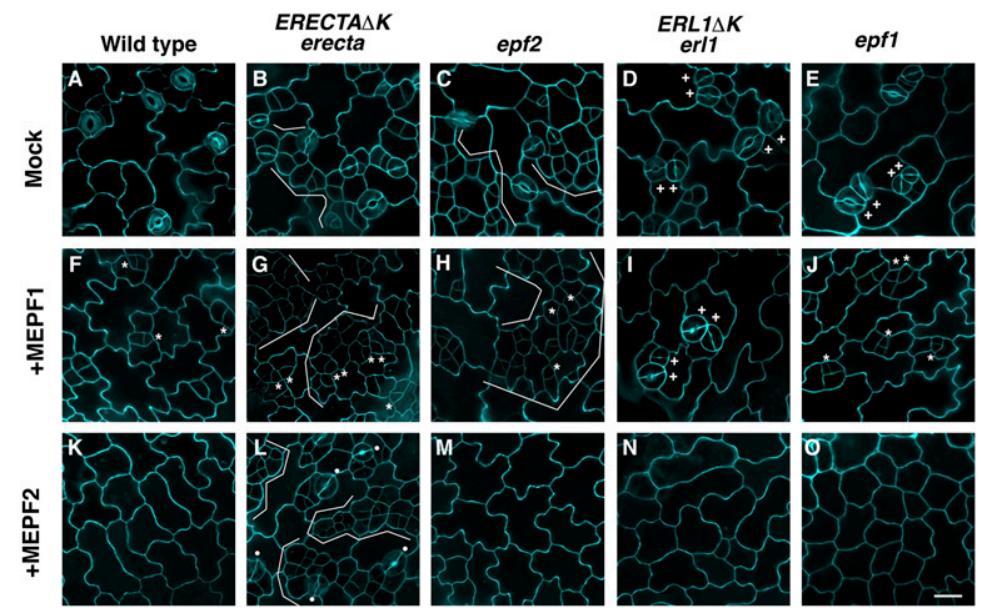

Figure 5. Blocking ERECTA and ERL1 signaling with dominant-negative receptors confers specific insensitivity to EPF2 and EPF1, respectively. Confocal microscopy of liquid cultured 6-d-old abaxial cotyledons from wild type $(\mathrm{WT} ; A, F, K)$, ERECTA $\Delta \mathrm{K}$ in erecta $(B, G, L)$, epf2 $(C, H, M)$, ERL1 $1 \Delta \mathrm{K}$ in erl1 $(D, I, N)$, and epf1 $(E, J, O)$. These seedlings were incubated with buffer only (mock; $A-E)$, buffer with $2.5 \mu \mathrm{M}$ MEPF1 (+MEPF1; F-J), or buffer with $2.5 \mu \mathrm{M}$ MEPF2 (+MEPF2; $K-O)$. $(B, C)$ Both ERECTA $\Delta \mathrm{K}$ in erecta and epf2 mutation confer excessive entry asymmetric divisions (brackets). $(D, E)$ Both ERL1 $\Delta \mathrm{K}$ in erl1 and epf1 mutation confer stomatal pairing (plus). (I) MEPF1 application confers an epidermis devoid of stomata but with arrested meristemoids (asterisks) in all genotypes except for ERL1 $\Delta \mathrm{K}$ in er11, which produces paired stomata (plus). (L) MEPF2 application leads to severe inhibition of asymmetric division in all genotypes except for ERECTA $\Delta \mathrm{K}$ in erecta. Images were taken under the same magnification. Bar, $20 \mu \mathrm{m}$. Peptide application experiments were performed at least three times. For additional genotypes and quantitative analysis, see Supplemental Fig. 11.

Fig. 11G,H,J). None of the genotypes showed significant changes in stomatal density (Supplemental Fig. 11I). The results place ERECTA and ERL1 as major receptors for EPF2- and EPF1-mediated signaling during stomatal development, respectively.

To ultimately address the in vivo specificity of EPF2ERECTA and EPF1-ERL1 ligand-receptor pairs, we treated seedlings with bioactive MEPF1 and MEPF2 (Fig. 5F-O). MEPF1 application to wild type, epf1, epf2, and ERECTA $\triangle K$ in erecta conferred arrested meristemoids (Fig. $5 \mathrm{~F}-\mathrm{H}, \mathrm{J}$ ), indicating that MEPF1 is triggering a cellular response. Consistent with the separate roles of EPF1 and EPF2, upon MEPF1 application, seedlings of epf2 and ERECTA $\triangle K$ in erecta exhibited additive phenotypes: excessive asymmetric divisions, none of which differentiate into stomata (Fig. 5G,H). In contrast, seedlings of ERL1AK in erl1 developed paired stomata even in the presence of MEPF1 (Fig. 5I), indicating that $E R L 1 \Delta K$ confers insensitivity to MEPF1 application. Similarly, seedlings of ERECTA $\triangle K$ in erecta are insensitive to MEPF2 application and differentiate stomata (Fig. 5L), while seedlings of all other genotypes (wild type, epf1, epf2, and ERL1AK in erl1) showed severe inhibition of asymmetric division and stomatal development (Fig. 5K,M-O). Based on these findings, we conclude that EPF1 and EPF2 act as specific, upstream signaling ligands for ERL1- and ERECTA-mediated signal transduction, respectively.

\section{Discussion}

Our study demonstrates direct ligand-receptor binding and receptor-receptor association and establishes the molecular framework of cell-cell communication in stomatal patterning. Our work indicates that ERECTA family RKs act as the primary receptors that directly bind MEPF peptides and that EPF2-ERECTA and EPF1-ERL1 constitute in vivo ligand-receptor pairs specifying two consecutive steps of stomatal development: asymmetric entry divisions and spacing divisions, respectively (Supplemen- tal Fig. 12). TMM, on the other hand, likely modulates the activity of the ERECTA family via heterodimerization (Supplemental Fig. 12).

The biochemical evidence supports the complex genetic interactions between TMM and the ERECTA family (Shpak et al. 2005; Abrash and Bergmann 2010; Abrash et al. 2011). For instance, TMM acts antagonistically on ERL1-mediated inhibition of stomatal differentiation (Shpak et al. 2005). This may represent a mechanism preventing the autocatalytic inhibition of stomatal differentiation (Supplemental Fig. 12): In the stomatal precursor cells that secrete MEPF1, TMM may titrate the pool of active ERL1 homodimers and prevent the signal transduction that would repress proper stomatal development. On the other hand, the cooperative role of the ERECTA family and $T M M$ in stomatal spacing suggests that, in nonstomatal neighboring cells, TMM may be required for proper function of the ERECTA family. The ability of TMM to associate with ERECTA in vivo and weakly bind MEPF2 (Figs. 1, 2, 4; Supplemental Fig. 8) implies that under normal conditions, TMM may have an additional role in finetuning the EPF2-ERECTA signaling to prevent signal interferences from other EPFs (Supplemental Fig. 12). In this regard, it is interesting that recently, Abrash et al. (2011) reported that loss-of-function mutations of three EPFL genes-EPFL6/CHAL, EPFL5/CHAL-LIKE1 (CLL1), and EPFL4/CLL2-influence stomatal patterning only in the tmm loss-of-function mutant background. None of these EPFL genes is expressed in the epidermis or affects stomatal patterning in the wild-type background, further supporting the idea that TMM acts as an insulator of EPF/EPFL signals during stomatal development.

While ERECTA family RKs show robust binding to both MEPF1 and MEPF2 in vitro as well as in the heterologous $N$. benthamiana system (Figs. 1, 2), they exhibit striking specificities in vivo during stomatal development (Fig. 5; Supplemental Fig. 11). How can these two observations be reconciled? It is possible that MEPFs could bind to any ERECTA family RKs, but "improper" ligand-receptor 
combinations would not trigger receptor activation or signal transduction. ERECTA is expressed in the entire protoderm, while ERL1 expression in the epidermis is restricted to stomatal cell lineages (Shpak et al. 2005). Thus, alternatively, a different ratio of each receptor species in each stomatal precursor cell may contribute to in vivo specificity.

ERECTA family RKs show unequal redundancies during stomatal development (Shpak et al. 2004, 2005), implying that despite the observed in vivo specificities of EPF2-ERECTA and EPF1-ERL1 ligand-receptor pairs, each receptor could transmit overlapping EPF signals. This inconsistency can be reconciled based on our knowledge of dominant-negative ERECTA (Shpak et al. 2003). We propose that in addition to specific functions of ERECTA family homodimers, ERECTA-ERL heterodimers contribute to unequal redundancy (Supplemental Fig. 12). The dominant-negative (kinase-deleted) ERECTA receptor protein is highly stable, and its ligand-binding capacity is unaffected (Fig. 1; Shpak et al. 2003). Therefore, the expression of ERECTA $\Delta \mathrm{K}$ and ERL1 $\Delta \mathrm{K}$ in their respective null mutant backgrounds would result in complete blockage of EPF2 and EPF1 signals, respectively, regardless of the presence of remaining ERECTA family heterodimers or a signal modulator, TMM. For instance, dominant-negative ERECTA receptor expressed in erecta would form nonfunctional receptor homodimers as well as nonfunctional receptor heterodimers with the endogenous ERLs and block EPF2-mediated signal transduction. Deciphering the exact mechanism of such intricate redundancy would be an exciting future direction.

The proposed mode of action of ERECTA family/TMM coreceptors is different from other well-studied LRR-RKs, including BRI1, FLS2, and CLV1 (Belkhadir and Chory 2006; Muller et al. 2008; Zipfel 2008). The CLV pathway involves an LRR-RK CLV1, which is structurally analogous to the ERECTA family, and an LRR-RLP CLV2, which is structurally analogous to TMM (Clark et al. 1997; Jeong et al. 1999|. However, these two systems act in fundamentally different manners: CLV2 associates with CORYNE (CRN), which possesses transmembrane and cytoplasmic kinase domains but lacks an extracellular LRR domain, and both CLV1 homomers and CLV2/CRN heteromers transmit CLV3-mediated signals in parallel (Muller et al. 2008). Thus, activation and signal transduction by LRRRKs may be diverse and versatile.

Our work highlights the intricate balance of ligands and receptors critical for cell fate specification and provides new insight into how cells decode related signals using the same set of receptors to achieve complex tissue patterning in plants. The production of bioactive MEPF peptides that elicit unique developmental responses will also enable investigation of the structural basis of ligand specificity, affinity, and dynamics in the future.

\section{Materials and methods}

Plant materials

Arabidopsis thaliana Columbia (Col) accession was used as wild type. Mutants and transgenic lines used in this study are in the
Col background unless otherwise specified. The following mutants and transgenic lines have been described previously: er-105, er11-2, and er-105 er11-2 erl2-1 (Shpak et al. 2004, 2005); epf1 and tmm-KO (Hara et al. 2007); epf2 (Hara et al. 2009); and pNLB115 (proERECTA::ERECTA-3xFlag) in er-105 (Uchida et al. 2011). Each transgene was introduced into its respective mutant background by either Agrobacterium-mediated transformation or genetic crosses. Arabidopsis seeds were surface-sterilized with bleach solution (33\% bleach solution, $0.01 \%$ Triton X-100) and grown on Murashige-Skoog(MS) medium. Two-week-old seedlings were transplanted onto soil and grown as described previously (Shpak et al. 2003). N. benthamiana was grown in a temperature-controlled growth room maintained with a $16-\mathrm{h}$ light $/ 8$-h dark cycle at $25^{\circ} \mathrm{C}$. Three-week-old to 4-wk-old plants were used for experiments.

\section{Plasmid construction and generation of transgenic plants}

The following constructs were generated and used in this study: pMK111 (proERL1::3xFlag), pMK110 and pMK210 (proERL1:: ERL1-YFP), pMK112 and pMK212 (proERL1::ERL1-3xFlag), pJG102 (proTMM::TMM-3xHA), pJM125 (proTMM::TMM), pJM251 (proTMM::TMM-YFP), pJM122 (TMM cDNA), pJM140 (ERL1 $\Delta \mathrm{K}$ ), pJM154 and pJM254 (proERECTA::ERECTA $\Delta$ K-YFP), pJM159 and pJM259 (proERL1::ERL1 1 K-CFP), pJM184 and pJM284 (proERECTA::ERECTA-YFP), pTK102 (proEst::EPF1), pTK103 (proEst::EPF2), pTK127 (EPF1 cDNA), pTK128 (EPF2 cDNA), pMK334 (LURE2 cDNA), pTK146 (ERECTA $\Delta$ K), pJSL55 (CaMV35S::ERECTA $\triangle$ K-GFP), pJSL56 (CaMV35S::ERL1 $\Delta$ K-GFP), pJSL57 (CaMV35S::TMM-GFP), pJSL51 (EPF1-3xFlag), pJSL52 (EPF2-3xFlag), pJSL77 (LURE2-3xFlag), pJSL59 (CaMV35S:: EPF1-3xFlag), pJSL60 (CaMV35S::EPF2-3xFlag), pJSL81 (CaMV35S:: LURE2-3xFlag), pJSL11 (pBAD::MEPF1-6xHis), and pJSL68 (pBAD:: MEPF2-6xHis). Genomic clones of ERECTA and ERL1 were used for all epitope-tagged constructs. Stable transgenic plants were generated using Agrobacterium-mediated transformation by the floral-dip method (Clough and Bent 1998). The epitope-tagged receptors were transformed into their respective knockout (null) mutant backgrounds to confirm their functionality via complementation. For all transgenic Arabidopsis lines, $>20$ T1 plants per construct were subjected to phenotypic characterization. Two to three lines were selected based on single insertion status inferred by the segregation of resistance genes and stability of the phenotype in subsequent generations. For information on the plasmid construction and primers used in this study, see Supplemental Tables 1 and 2.

\section{Histochemical analysis and microscopy}

For confocal microscopy, seedlings were treated with propidium iodide (PI) (Sigma) to highlight cell periphery (excitation, $555 \mathrm{~nm}$; emission, $570-610 \mathrm{~nm}$ ) using a Zeiss LSM700 with a $20 \times$ objective lens. Histochemical staining of epidermis using toluidine blue O (TBO) (Sigma) was performed as described in Hara et al. (2009). Quantitative analysis of stomatal phenotypes was performed using TBO-stained epidermal samples as described previously (Guseman et al. 2010).

Preparation of membrane proteins, co-IP, and protein gel immunoblot analysis

For co-IP assays, Arabidopsis plants expressing functional, epitopetagged receptor proteins that complement the respective mutant phenotypes were used as starting materials. Twelve-day-old Arabidopsis seedlings were ground to fine powder in liquid nitrogen and solubilized with $3 \times(\mathrm{w} / \mathrm{v})$ extraction buffer $(100 \mathrm{mM}$ Tris- $\mathrm{HCl}$ at $\mathrm{pH} 8.8,150 \mathrm{mM} \mathrm{NaCl}, 1 \mathrm{mM}$ EDTA, 20\% glycerol, 
$20 \mathrm{mM}$ NaF, $1 \mathrm{mM}$ PMSF, 1:1000 Complete protease inhibitor cocktail [Sigma]). The extracts were sonicated on ice and ultracentrifuged at $100,000 \mathrm{~g}$ for $30 \mathrm{~min}$ at $4^{\circ} \mathrm{C}$ to obtain the membrane fraction as precipitate. The pellet was resuspended in membrane solubilization buffer (100 mM Tris- $\mathrm{HCl}$ at $\mathrm{pH} 7.3,150 \mathrm{mM} \mathrm{NaCl}$, $1 \mathrm{mM}$ EDTA, $10 \%$ glycerol, $1 \%$ Triton $\mathrm{X}-100,20 \mathrm{mM} \mathrm{NaF}, 1 \mathrm{mM}$ PMSF, 1:1000 Complete protease inhibitor cocktail) to release membrane proteins. The solution was sonicated on ice and ultracentrifuged again at $100,000 \mathrm{~g}$ for $30 \mathrm{~min}$ at $4^{\circ} \mathrm{C}$, and the supernatant was incubated with anti-GFP (ab290, Abcam) or anti$\mathrm{HA}$ (Sigma) overnight at $4^{\circ} \mathrm{C}$. Immune complexes were bound to protein G-agarose beads (Pierce) for $1.5 \mathrm{~h}$ with slow rotation at $4^{\circ} \mathrm{C}$, followed by washing in IP buffer $(25 \mathrm{mM}$ Tris- $\mathrm{HCl}$ at $\mathrm{pH} 7.2$, $150 \mathrm{mM} \mathrm{NaCl}$ ) four times. The immunoprecipitates were eluted with $2 \times$ SDS sample buffer $(200 \mathrm{mM}$ Tris- $\mathrm{HCl}$ at $\mathrm{pH} 6.8,8 \%$ SDS, $0.4 \%$ Bromophenol Blue, $40 \%$ glycerol, $10 \% \beta$-mercaptoethanol) by boiling for $5 \mathrm{~min}$. Either total membrane or immunoprecipitated proteins were separated on a SDS-PAGE gel and transferred to PDVF membrane (Millipore) for immunoblot analysis using monoclonal anti-Flag M2 (Sigma), mouse anti-GFP (Zymed Laboratory), or mouse anti-HA (12CA5, Roche) antibodies as primary antibodies. As secondary antibodies, goat anti-mouse IgG horseradish peroxidase-linked antibodies (GE Healthcare) were used at a dilution of 1:50,000. The protein blots were visualized using Chemiluminescence assay kit (Thermo Scientific).

Transient protein expression in $\mathrm{N}$. benthamiana by agroinfiltration

Agrobacterium tumefaciens strain GV3101 was transformed with the indicated expression clones and grown in YEB medium supplemented with kanamycin and hygromycin. Bacterial cultures were precipitated and resuspended in infiltration medium containing $10 \mathrm{mM} \mathrm{MgCl}_{2}, 10 \mathrm{mM}$ MES (pH 5.6), and $150 \mu \mathrm{M}$ acetosyringone. To enhance the transient expression in tobacco, cultures were mixed with an Agrobacterium culture that allows expression of the silencing suppressor p19 (a gift from Professor Sir David Baulcomb) (Voinnet et al. 2003), giving an optical density at $600 \mathrm{~nm}$ of 0.3 for each strain. The mixed bacterial suspensions were then infiltrated into young, but fully expanded, leaves of $N$. benthamiana plants using a needleless syringe. After infiltration, plants were grown further for $48-72 \mathrm{~h}$ at $25^{\circ} \mathrm{C}$ and collected for further biochemical assays.

\section{Immunopurification of EPFs from $\mathrm{N}$. benthamiana}

Tobacco leaves expressing MEPF1-Flag or MEPF2-Flag were ground in liquid nitrogen and homogenized in extraction buffer $(100 \mathrm{mM}$ HEPES at $\mathrm{pH} 7.5,5 \mathrm{mM}$ EDTA, $5 \mathrm{mM}$ EGTA, $150 \mathrm{mM} \mathrm{NaCl}, 2 \mathrm{mM}$ $\mathrm{Na}_{3} \mathrm{VO}_{4}, 2 \mathrm{mM} \mathrm{NaF}, 1 \mathrm{mM}$ PMSF, 1 tablet $/ 50 \mathrm{~mL}$ extraction buffer of protease inhibitor mixture [Roche Applied Science], 10\% glycerol, $7.5 \%[\mathrm{w} / \mathrm{v}]$ PVPP). After centrifugation at $10,000 \mathrm{~g}$ for $15 \mathrm{~min}$ at $4{ }^{\circ} \mathrm{C}$, the supernatant was filtered through a $0.45-\mu \mathrm{m}$ filter. The filtrate was then incubated with prewashed anti-Flag M2 affinity gel (Sigma-Aldrich) overnight at $4^{\circ} \mathrm{C}$, washed extensively, and eluted by either competition with Flag peptide (Sigma-Aldrich) or acid elution with glycine. The immunopurified EPF1 and EPF2 were subjected to bioassays.

\section{Chemical induction of transgenes}

Transgenic Arabidopsis seedlings carrying estradiol-inducible EPF1 and EPF2 were germinated on MS medium supplemented with $5 \mu \mathrm{M}$ estradiol (Sigma). Induction of EPF1 and EPF2 gene expression was confirmed by RT-PCR. The induction was confirmed by observing the epidermal phenotypes of cotyledons and rosette leaves using a confocal microscope.
Expression, purification, refolding, and bioassays of recombinant MEPF peptides

Recombinant LURE2 peptide was prepared according to Okuda et al. (2009). For preparation of recombinant MEPF1 and MEPF2, the following modifications were employed. Coding sequences of predicted MEPF1 and MEPF2 were amplified from the cDNA of Arabidopsis and cloned into the vector pBAD/gIII A (Invitrogen) to fuse a poly-histidine (His) tag to the $\mathrm{C}$ terminus. Peptides were expressed in $E$. coli overnight at $37^{\circ} \mathrm{C}$ and purified by a $\mathrm{Ni}$ column (His-Trap FF, GE Healthcare). The recombinant peptides were dialyzed (Mini dialysis kit, MWCO:1,000, GE Healthcare) and refolded for $4 \mathrm{~d}$ at $4^{\circ} \mathrm{C}$ using glutathione (reduced and oxidized forms; Wako) and L-arginine ethyl ester dihydrochloride (Sigma). For heat denaturation experiments, refolded peptide solution was incubated for $30 \mathrm{~min}$ at $70^{\circ} \mathrm{C}$. For bioassays, either buffer alone (50 mM Tris- $\mathrm{HCl}$ at $\mathrm{pH} 8.0$ ) or refolded recombinant MEPF peptides in buffer were applied to 1-d-old Arabidopsis plants that had germinated on MS medium. After $5 \mathrm{~d}$ of further incubation in MS liquid medium containing each peptide, stomatal phenotypes of abaxial cotyledons were determined by inspection with a confocal microscope.

\section{HPLC purification and MALDI-TOF mass spectrometry analysis}

Affinity column-purified MEPF1 and MEPF2 were further purified on reverse-phase HPLC (Waters Delta Prep 3000 HPLC) to assess MEPF1 and MEPF2 conformational isomers. The solvents used were solvent A, $0.1 \%$ TFA in DI water; and solvent B, 75\% acetonitrile, $1 \mathrm{~mL} / \mathrm{min}$ flow rate using the following gradient program: $0-2 \mathrm{~min}$ in an isocratic flow $(0 \% \mathrm{~B}), 2-102 \mathrm{~min}$ in a linear gradient of $1 \%$ per minute, and $102-117 \mathrm{~min}$ in an isocratic flow $(0 \% \mathrm{~A})$. The separated peaks were collected by autothreshold collection, and the peaks' contents were identified by MALDITOF mass spectrometry on an Autoflex II mass spectrometer in positive ion mode (Bruker Daltonics) using 2:1 $\alpha$-cyano-4hydroxycinnamic acid and 2,5-dihydroxy-benzoic acid matrix. The collected HPLC-purified MEPF1 and MEPF2 peptide peaks were freeze-dried, then redissolved to appropriate concentration in MS-0 medium, and used for bioassays.

\section{Preparation of biosensor surfaces}

Gold-coated QCM and SPR slides of the specifications described below were used after cleaning by sequential sonication in acetone, ethanol, and water (three times per solvent, 5 min each) followed by UV ozone cleaning for $20 \mathrm{~min}$. The GFP-tagged receptors were immobilized on clean chip surfaces via anti-GFP antibody linkage. First, the surfaces were drop-incubated with 1:50 dilution of anti-GFP solution (ab290, Abcam) in phosphate buffer ( $\mathrm{pH}$ 7.4) in a humidity-controlled environment overnight at $4^{\circ} \mathrm{C}$ and rinsed 10 times by dilution rinse with phosphate buffer. The surfaces were then blocked in a $2 \%$ bovine serum albumin (BSA) solution for $2 \mathrm{~h}$ and washed by dilution as before. The resulting samples were incubated with a membrane fraction of either control (GFP only) or receptor solution for either $4 \mathrm{~h}$ (QCM) or $2 \mathrm{~h}$ (SPR), followed by the dilution rinse and an additional $1 \mathrm{~h}$ of BSA blocking to yield receptor-immobilized biosensor chips. All chips were used on the day they were produced.

\section{QCM}

QCM measurements were performed using QCM-Z500 (KSV Instruments) and commercially available AT-cut polished QCM crystals with a fundamental resonant frequency of $4.95 \mathrm{MHz}$ 
(International Crystal Manufacturing Co.). The sensor surface was precoated by evaporation with a $100 \AA$ titanium adhesion layer, followed by $1000 \AA$ of gold. The QCM crystal dimensions used were $1.397 \mathrm{~cm}$ (0.550 in) blank diameter and $0.5 \mathrm{~cm}$ and $1.176 \mathrm{~cm}(0.440 \mathrm{in})$ wraparound electrode diameters. The receptormodified QCM crystal (described above) was placed in the holder and sealed with two O-rings. In order to establish a stable baseline, a sufficient amount of phosphate buffer solution was injected to fill the QCM chamber, and the frequency shifts were monitored overnight. Then, sequential serial concentrations of recombinant MEPF1 or MEPF2 peptides in phosphate buffer solution were introduced to the QCM chamber, and the frequency change was recorded continuously until no further change was observed, indicating equilibrium. The QCM resonant frequency shifts recorded at the seventh harmonic were used to analyze ligand-receptor interactions, since the observed resonant QCM frequency decreases proportionally to the mass of adsorbed molecules following the Saurbrey equation

$$
\Delta \mathrm{f}=-\left[2 \times \mathrm{f}_{0}^{2} \times \Delta \mathrm{m}\right] /\left[\mathrm{A} \times\left(\rho_{\mathrm{q}} \times \mu_{\mathrm{q}}\right)^{1 / 2}\right],
$$

where $f_{0}$ is the frequency of the fundamental mode of the crystal, $\Delta \mathrm{m}$ is the mass change per unit area, $\mathrm{A}$ is the piezoelectrically active area, $\rho_{\mathrm{q}}$ is the density of quartz, and $\mu_{\mathrm{q}}$ is the shear modulus of quartz. All experiments were performed at $4^{\circ} \mathrm{C}$ in stopflow mode in three independent experiments.

\section{$S P R$}

SPR measurements were made on a four-channel instrument (Kretschmann configuration: Radio Engineering Institute, Czech Republic) equipped with a polychromatic light source (Ocean Optics LS1). The slides were prepared via thermal evaporation by coating a BK-7 glass slide with $20 \AA$ of chromium as the adhesion layer and $480 \AA$ of gold. The instrument can detect changes at a level of 0.0001 refractive index unit and is temperature controlled $\left(10^{\circ} \mathrm{C}-55^{\circ} \mathrm{C}\right)$. Buffer and recombinant MEPF solutions were degassed to avoid bubble formation in the flow cell. First, phosphate buffer solution was flowed over the surface until a stable baseline signal was established $\mid<0.05 \mathrm{~nm}$ change over 5 $\mathrm{min})$. Then, recombinant MEPF solutions in phosphate buffer at concentrations indicated were flowed over the surface, and the adsorption was monitored. The temperature within the flow cell of the SPR was kept at a constant $25^{\circ} \mathrm{C}$ via a heating element and a cooling fan controlled by a temperature controller. All of the solutions used were introduced to the flow cell at a rate of $140 \mu \mathrm{L} / \mathrm{sec}$. The Langmuir isotherm model was used to calculate the kinetics of the adsorption process using the experimental data obtained from SPR experiments as described previously (Tamerler et al. 2006), by fitting the following equation to the adsorption data:

$$
\Delta n=n_{\max }\left(1-e^{-k_{o b s} t}\right),
$$

where $\Delta n$ is the plasmon resonance peak shift in nanometers, $n_{\max }$ is the expected sift ath equilibrium, $k_{\text {obs }}$ is the apparent rate of adsorption, and $t$ is time in seconds.

\section{Acknowledgments}

This manuscript is dedicated to the memory of Laura Sheard, who inspired us to explore the biochemical and structural basis of ligand-receptor interactions. We thank J. Guseman, R. Virata, H. Lai, and J. Sagawa for technical assistance and plant care; Sir D. Baulcombe for p19 plasmid; T. Imaizumi for technical advice on co-IP; N. Sasaki and T. Higashiyama for refolding protocols; and S. Betsuyaku for agroinfiltration protocols. We also thank J. Nemhauser, K. Peterson, T. Imaizumi, and L. Pillitteri for commenting on the manuscript. This work was supported by NSF IOS-0520548, IOS-0744892, and the JST PRESTO award to K.U.T., and the NSF-MRSEC program to M.S. and C.T. The SPR/ QCM experiments were carried out at the GEMSEC Shared Experimental Facilities, part of the MRSEC-Materials Research Facilities Network. J.S.L. is a recipient of the Canadian NSERC post-doctoral fellowship, and K.U.T. is an HHMI-GBMF investigator. K.U.T. directed the entire project. K.U.T. and J.S.L. designed the experiments. J.S.L. performed confocal microscopy. T.K. and J.S.L. performed co-IP assays. J.S.L. and M.M.K. purified and refolded MEPF1/2 and LURE2 peptides, respectively. J.S.L, M.H., and D.K. performed SPR and QCM experiments and analyzed the data with M.S. and C.T. K.U.T. performed quantitative analysis of epidermis. J.S.L., T.K., M.M.K., and J.M.M. made constructs. K.U.T., J.S.L., and M.H. wrote the manuscript with input from the coauthors.

\section{References}

Abrash EB, Bergmann DC. 2010. Regional specification of stomatal production by the putative ligand CHALLAH. Development 137: 447-455.

Abrash EB, Davies KA, Bergmann DC. 2011. Generation of signaling specificity in Arabidopsis by spatially restricted buffering of ligand-receptor interactions. Plant Cell. 23: 2864-2879.

Baltus RE, Carmon KS, Luck LA. 2007. Quartz crystal microbalance (QCM) with immobilized protein receptors: Comparison of response to ligand binding for direct protein immobilization and protein attachment via disulfide linker. Langmuir 23: 3880-3885.

Belkhadir Y, Chory J. 2006. Brassinosteroid signaling: A paradigm for steroid hormone signaling from the cell surface. Science 314: 1410-1411.

Clark SE, Williams RW, Meyerowitz EM. 1997. The CLAVATA1 gene encodes a putative receptor kinase that controls shoot and floral meristem size in Arabidopsis. Cell 89: 575-585.

Clough SJ, Bent AF. 1998. Floral dip: A simplified method for Agrobacterium-mediated transformation of Arabidopsis thaliana. Plant J 16: 735-743.

De Smet I, Voss U, Jurgens G, Beeckman T. 2009. Receptor-like kinases shape the plant. Nat Cell Biol 11: 1166-1173.

Gray JE, Casson S, Hunt L. 2008. Intercellular peptide signals regulate plant meristematic cell fate decisions. Sci Signal 1: pe53. doi: 10.1126/scisignal.149pe53.

Guseman JM, Lee JS, Bogenschutz NL, Peterson KM, Virata RE, Xie B, Kanaoka MM, Hong Z, Torii KU. 2010. Dysregulation of cell-to-cell connectivity and stomatal patterning by lossof-function mutation in Arabidopsis CHORUS (GLUCAN SYNTHASE-LIKE 8). Development 137: 1731-1741.

Hara K, Kajita R, Torii KU, Bergmann DC, Kakimoto T. 2007. The secretory peptide gene EPF1 enforces the stomatal onecell-spacing rule. Genes Dev 21: 1720-1725.

Hara K, Yokoo T, Kajita R, Onishi T, Yahata S, Peterson KM, Torii $\mathrm{KU}$, Kakimoto T. 2009. Epidermal cell density is auto-regulated via a secretory peptide, EPIDERMAL PATTERNING FACTOR2 in Arabidopsis leaves. Plant Cell Physiol 50: 1019-1031.

Higashiyama T. 2010. Peptide signaling in pollen-pistil interactions. Plant Cell Physiol 51: 177-189.

Hunt L, Gray JE. 2009. The signaling peptide EPF2 controls asymmetric cell divisions during stomatal development. Curr Biol 19: 864-869.

Jeong S, Trotochaud AE, Clark SE. 1999. The Arabidopsis CLAVATA2 gene encodes a receptor-like protein required 
Lee et al.

for the stability of the CLAVATA1 receptor-like kinase. Plant Cell 11: 1925-1933.

Karve R, Liu W, Willet SG, Torii KU, Shpak ED. 2011. The presence of multiple introns is essential for ERECTA expression in Arabidopsis. RNA 17: 1907-1921.

Kondo T, Kajita R, Miyazaki A, Hokoyama M, Nakamura-Miura T, Mizuno S, Masuda Y, Irie K, Tanaka Y, Takada S, et al. 2010. Stomatal density is controlled by a mesophyll-derived signaling molecule. Plant Cell Physiol 51: 1-8.

Matsubayashi Y. 2010. Post-translational modifications in secreted peptide hormones in plants. Plant Cell Physiol 52: 5-13.

Muller R, Bleckmann A, Simon R. 2008. The receptor kinase CORYNE of Arabidopsis transmits the stem cell-limiting signal CLAVATA3 independently of CLAVATA1. Plant Cell 20: 934-946.

Nadeau JA, Sack FD. 2002. Control of stomatal distribution on the Arabidopsis leaf surface. Science 296: 1697-1700.

Ogawa M, Shinohara H, Sakagami Y, Matsubayashi Y. 2008. Arabidopsis CLV3 peptide directly binds CLV1 ectodomain. Science 319: 294.

Okuda S, Tsutsui H, Shiina K, Sprunck S, Takeuchi H, Yui R, Kasahara RD, Hamamura Y, Mizukami A, Susaki D, et al. 2009. Defensin-like polypeptide LUREs are pollen tube attractants secreted from synergid cells. Nature 458: 357-361.

Rowe MH, Bergmann DC. 2010. Complex signals for simple cells: The expanding ranks of signals and receptors guiding stomatal development. Curr Opin Plant Biol 13: 548-555.

Rychel AL, Peterson KM, Torii KU. 2010. Plant twitter: Ligands under 140 amino acids enforcing stomatal patterning. J Plant Res 123: 275-280.

Shimada T, Sugano SS, Hara-Nishimura I. 2011. Positive and negative peptide signals control stomatal density. Cell Mol Life Sci 68: 2081-2088.

Shinohara H, Ogawa M, Sakagami Y, Matsubayashi Y. 2007. Identification of ligand binding site of phytosulfokine receptor by on-column photoaffinity labeling. I Biol Chem 282: 124-131.

Shpak ED, Lakeman MB, Torii KU. 2003. Dominant-negative receptor uncovers redundancy in the Arabidopsis ERECTA leucin-rich repeat receptor-like kinase signaling pathway that regulates organ shape. Plant Cell 15: 1095-1110.

Shpak ED, Berthiaume CT, Hill EJ, Torii KU. 2004. Synergistic interaction of three ERECTA-family receptor-like kinases controls Arabidopsis organ growth and flower development by promoting cell proliferation. Development 131: 1491-1501.

Shpak ED, McAbee JM, Pillitteri LJ, Torii KU. 2005. Stomatal patterning and differentiation by synergistic interactions of receptor kinases. Science 309: 290-293.

Sugano SS, Shimada T, Imai Y, Okawa K, Tamai A, Mori M, Hara-Nishimura I. 2010. Stomagen positively regulates stomatal density in Arabidopsis. Nature 463: 241-244.

Tamerler C, Oren EE, Duman M, Venkatasubramanian E, Sarikaya M. 2006. Adsorption kinetics of an engineered gold binding peptide by surface plasmon resonance spectroscopy and a quartz crystal microbalance. Langmuir 22: 7712-7718.

Uchida N, Igari K, Bogenschutz NL, Torii KU, Tasaka M. 2011. Arabidopsis ERECTA-family receptor kinases mediate morphological alternations stimulated by activation of NB-LRRtype UNI proteins. Plant Cell Physiol 52: 804-814.

Voinnet O, Rivas S, Mestre P, Baulcombe D. 2003. An enhanced transient expression system in plants based on suppression of gene silencing by the p19 protein of tomato bushy stunt virus. Plant J 33: 949-956.

Zipfel C. 2008. Pattern-recognition receptors in plant innate immunity. Curr Opin Immunol 20: 10-16. 


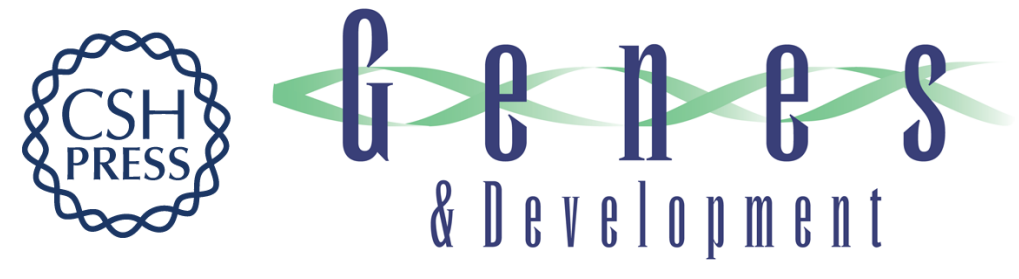

\section{Direct interaction of ligand-receptor pairs specifying stomatal patterning}

Jin Suk Lee, Takeshi Kuroha, Marketa Hnilova, et al.

Genes Dev. 2012, 26: originally published online January 12, 2012

Access the most recent version at doi:10.1101/gad.179895.111

\section{Supplemental http://genesdev.cshlp.org/content/suppl/2012/01/04/gad.179895.111.DC1 Material}

Related Content

Pairing Up for Patterning

Annalisa M. VanHook

Sci. Signal. February , 2012 5: ec44

References This article cites 33 articles, 15 of which can be accessed free at: http://genesdev.cshlp.org/content/26/2/126.full.html\#ref-list-1

Articles cited in:

http://genesdev.cshlp.org/content/26/2/126.full.html\#related-urls

License Freely available online through the Genes \& Development Open Access option.

Email Alerting Receive free email alerts when new articles cite this article - sign up in the box at the top Service right corner of the article or click here.

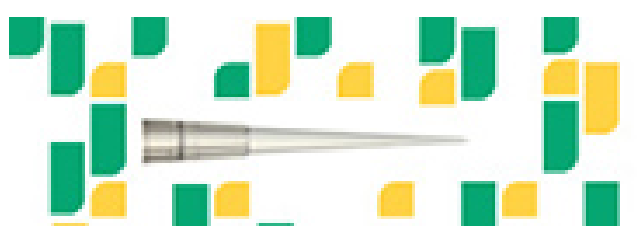

Focused on your science. 